\title{
Contribution to the Long-Term Shear Strength of a Needle Punched GCL
}

\author{
Helmut Zanzinger ${ }^{1}$ (D)
}

Received: 1 January 2016/Accepted: 23 February 2016/Published online: 7 March 2016

(C) Springer International Publishing Switzerland 2016

\begin{abstract}
For the evaluation of the long-term internal shear strength of a needle punched geosynthetic clay liner, long-term shear creep rupture tests have been carried out. The tests were carried out at elevated temperature of $80{ }^{\circ} \mathrm{C}$ in de-ionized water with the purpose to accelerate the creep of the fibres so that faster failure times are forced. A normal stress of $50 \mathrm{kPa}$ was applied while the shear stress was varied for each test. The test results showed that the time to shear failure directly depend on the applied shear stress and the shear stresses showed a clear correlation with failure times. The long-term internal shear stress has been determined through an extrapolation of the regression line at the test temperature of $80{ }^{\circ} \mathrm{C}$. In addition to lifetime prediction, the applicable shear stress was calculated for a minimum of 100 years under a normal stress of $50 \mathrm{kPa}$ at a given field temperature of $30^{\circ} \mathrm{C}$.
\end{abstract}

Keywords Geosynthetic clay liners - Long-term internal shear strength $\cdot$ Shear creep rupture test

\section{Introduction}

For the successful installation of GCLs on steep slopes of landfill cover systems, high internal shear strength of the GCL is the basic requirement. Typically GCLs consist of a woven and one or more nonwoven geotextiles (GTX) which encapsulate a bentonite layer. They are bonded by needle-punching and also called reinforced GCLs. In cases

Helmut Zanzinger

h.zanzinger@skz.de

1 SKZ - German Plastics Center, Friedrich-Bergius-Ring 22, 97076 Würzburg, Germany of a short-term design, the interface of a GCL to other geosynthetics (GSY) or to soil is mostly decisive. In a longterm design, the internal shear strength of the GCL will be more relevant.

Field tests do not help to answer the questions on the internal shear strength of reinforced GCLs. Until now there are no known failures in the field based on internal shear failure available. The failures happened so far were mostly because of inadequate shear strength in the interfaces to other GSYs. Especially the answer about the long-term internal shear strength can solely be simulated in suitable laboratory tests under accelerated conditions. Field tests might last decades until results could be found.

Also, there is a lack of information about the long-term interface shear strength of GCLs to e.g. textured geomembranes. This paper is focused on the applicable long-term shear stress internally-between the carrier and the cover layers of a GCL.

Thermoplastic materials such as polypropylene (PP) deform under static load. Creep and chemical ageing processes (e.g. oxidation) also influence the strength of the synthetic fibres over the long-term. The lifetime prediction of these GSYs is essential as GCLs have to demonstrate their performance for many years. In cases such as landfills; e.g. in Germany it is not allowed to use GSYs with a predicted lifetime of less than 100 years.

GCLs are mineral liners, which are widely used in applications such as landfill cover lining systems. The shear strength of soil can be described using Mohr-Coulomb failure criterion by a friction angle and cohesion. Bentonite is formed from volcanic ash with a high smectite content (montmorillonite) resulting in a high swelling capacity and low hydraulic conductivity [1]. In hydrated condition, bentonite has extremely low shear strength. For this reason, bentonite is used in geotechnical applications 
among others as slurry for borehole drilling and excavated trench support.

In the application as a mineral liner on the steep slopes of a landfill cover, the low friction property of hydrated bentonite in a GCL is a disadvantage for the stability of the capping system. Therefore reinforced GCLs were developed either as needle punched or stitch-bonded GCL [2] to achieve very high internal shear strength.

A first study has been published by Zanzinger and Saathoff [2] on a stitch-bonded GCL in which the determination of short-term and long-term internal shear strength has been discussed. The second study is described in this paper. Here shear creep rupture tests are performed on a needle punched GCL, which is the most widely used type of GCLs worldwide.

\section{Shear Creep Rupture Tests}

For the determination of the shear creep rupture of a GCL, a sample of Bentomat GDA ${ }^{\circledR}$ was used. It consists of $4500 \mathrm{~g} /$ $\mathrm{m}^{2}$ granulated sodium bentonite between a $100 \mathrm{~g} / \mathrm{m}^{2} \mathrm{PP}$ woven slit film tape yarn GTX and a $200 \mathrm{~g} / \mathrm{m}^{2}$ PP nonwoven GTX (Table 1). Both were needle punched together without any thermal treatment.

The PP raw material was stabilised with specific antioxidant packages consisting of hindered amine light stabilisers designed to withstand long-term oxidation attacks. In the long-term, the lifetime of the GCL might be limited by its oxidation resistance rather than by the creep rupture of the PP fibres.

The length and width of the reinforced test specimen is $200 \mathrm{~mm}$ in machine direction (MD) respectively $200 \mathrm{~mm}$ in cross machine direction (CMD) (Fig. 1). The specimen is placed between two perforated stainless steel nail plates (Fig. 2). The purpose of using nail plates in the laboratory is not to simulate field conditions. There is no landfill

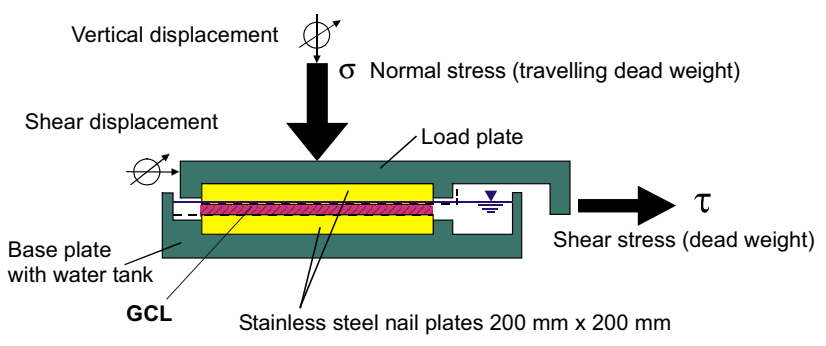

Fig. 1 Schematic cross section of the shear creep rupture test device

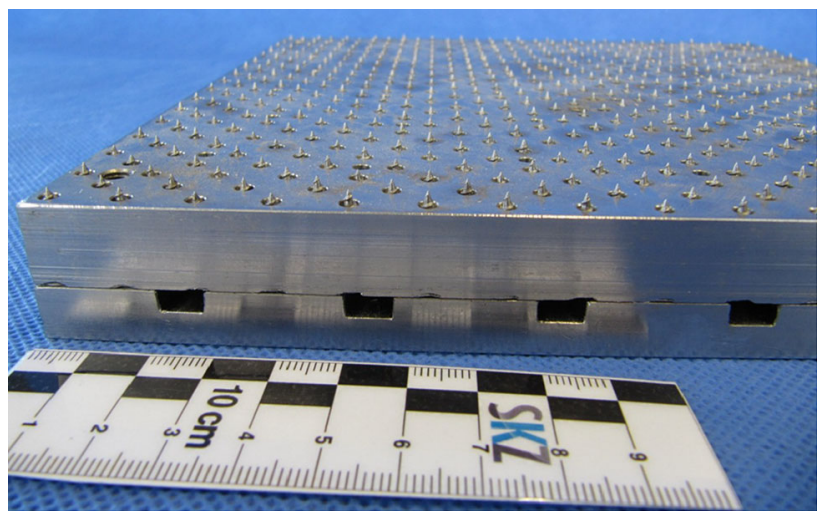

Fig. 2 Stainless steel nail plate $(200 \mathrm{~mm}$ by $200 \mathrm{~mm}$ ) with one nail per $\mathrm{cm}^{2}$ and 36 holes for watering and dewatering

where the GCL is placed between nail plates. The purpose is to provide a perfect homogenous shear stress distribution in the specimen to force an internal failure.

Between the nails, 36 holes have been drilled so that water can reach the GCL from both sides over the entire area of the specimen to increase the hydration rate of the bentonite. In preliminary tests with the same GCL and the same loading conditions it was found that around 3 days under a normal pressure of $50 \mathrm{kPa}$ were sufficient for complete hydration of the bentonite. Here for the moisture content of the bentonite was measured and different
Table 1 Characteristics of the GCL

\begin{tabular}{lll}
\hline Characteristic & Test method & Specification* \\
\hline Mass per unit area of GCL at 12\% moisture content & EN 14196 & $\geq 4300 \mathrm{~g} / \mathrm{m}^{2}$ \\
Mass per unit area of clay at $12 \%$ moisture content & & $\geq 4000 \mathrm{~g} / \mathrm{m}^{2}$ \\
Tensile strength MD/CMD & EN ISO 10319 & $\geq 9 \mathrm{kN} / \mathrm{m}$ \\
Strain at maximum load MD/CMD & & $\geq 10 \%$ \\
Push-trough force & EN ISO 12236 & $\geq 1.6 \mathrm{kN}$ \\
Average bonding peel strength MD & ASTM D6496a & $\geq 600 \mathrm{~N} / \mathrm{m}$ \\
Flux & ASTM D5887 & $\leq 5 \times 10^{-9} \mathrm{~m}^{3} /\left(\mathrm{m}^{2} \mathrm{~s}\right)$ \\
Swell index (24 h) & ASTM D5890 & $\geq 20 \mathrm{ml} / 2 \mathrm{~g}^{2}$ \\
Fluid loss volume & ASTM D5891 & $\leq 18 \mathrm{ml}$ \\
\hline
\end{tabular}

* Minimum values taken from the technical documentation $M D$ machine direction, $C M D$ cross machine direction 
locations and stable moisture content with a homogeneous distribution was determined. Without watering holes in the nail plates, the hydration of a dry GCL must develop from the edges of the specimen to the centre. From the experience, it has been learnt that without watering holes the GCL is hydrated only at the edges and the centre of the specimen would still be unhydrated. As unhydrated bentonite may have a very high shear strength, test results will be extremely affected especially under very high shear loads when the rupture occurs early.

Nail plates have to be stable, corrosion resistant and also temperature resistant so that they remain even during the complete test duration. They have to guarantee a perfect interlocking with the geotextile components over the entire specimen area. The geotextiles shall not to be tensioned during the test.

In a previous examination with tap water (Table 2), the GCL was loaded in a shear creep test at $80{ }^{\circ} \mathrm{C}$ for $11,300 \mathrm{~h}$ under a normal load of $50 \mathrm{kPa}$. Due to evaporation, the water bath must always be refilled with de-ionized (DI) water to keep the specimen entirely immersed under water. The water properties were changed $\left(\mathrm{Ca}^{2+}\right.$ ions in the tap water were taken by the bentonite) due to sodium to calcium ion exchange.

Müller et al. [3] stated that a total exchange from sodium to calcium will take place within a few years. From this point of view, it might be justified to test with tap water instead of with DI water in laboratory tests. In the authors' opinion, it could only be taken into account for projects where a complete cation exchange of a sodium bentonite GCL is guaranteed. In such a case, the lifetime of a GCL would be extended due to the fact that the stress in the fibres will decrease somehow. Under safety aspects, such effects should be used as additional safety factors rather than using it in a stability analysis. In the described study on the needle punched GCL, DI water was used and therefore a cation exchange from sodium to calcium bentonite did not happen even after $6000 \mathrm{~h}$ of immersion (Table 2).

The testing of the needle punched GCL followed the same procedure as described by Zanzinger and Saathoff [2] using the same shear creep rupture test device (Fig. 3).
Sixteen specimens of the GCL were tested at different shear stresses (Fig. 4). The test results are shown in a shear creep rupture diagram (Fig. 5) using the results given in Table 3. The regression curve shows a correlation factor of 0.77 . The curves of the lower and upper $95 \%$ confidence limits are also shown. One test out of 16 with a shear stress of $50 \mathrm{kPa}$ has been terminated after $t_{\max }=7519 \mathrm{~h}$ before rupture.

The method for a forecast of design life at test temperature has been explained by Zanzinger and Saathoff [2]. For a design life $t_{d}=10 t_{\max }=75,192 \mathrm{~h}$, with the contributory factor $R_{1}=1.0$, the extrapolation is an extension of a straight line of the regression line (Fig. 6). For $t_{d}>75,192 \mathrm{~h}$, with $R_{1}=1.2$, the extrapolation shows a knee taking the uncertainty of a further extrapolation of creep-rupture data into account. The predicted applicable shear strength of the needle punched GCL at a temperature of $80{ }^{\circ} \mathrm{C}$ is around $25 \mathrm{kPa}$ for 85 years (Fig. 6).

Time dependent effects can be calculated by using the Arrhenius equation [2]. Müller et al. [3, 4] gave $E_{A}=65 \mathrm{~kJ} / \mathrm{mol}$ for PP geotextiles as lower limit of the activation energy. In Fig. 7 , the lifetime prediction is therefore calculated with activation energy of $65 \mathrm{~kJ} / \mathrm{mol}$ and shown as a bold line shifted by a high time shift factor of 38.52 on the time axis. From this line, the long-term shear strength can be taken for any duration. A field temperature of $30{ }^{\circ} \mathrm{C}$ was used as such a temperature is requested as long-term field temperature for covers of municipal solid waste landfills in Germany [5, 6]. For comparison a second line is also shown in Fig. 7 for extreme low activation energy of $32.8 \mathrm{~kJ} / \mathrm{mol}$, given by $\mathrm{Li}$ and Hsuan [7] for a PP woven slit film tape GTX based on the time for consumption of antioxidants only and not also on the polymer degradation. The time shift factor is here for 6.31 only. In the following figures, most calculations are based on $E_{A}=65 \mathrm{~kJ} / \mathrm{mol}$ as the used PP GTXs (Table 4, samples no. 7 and no. 10) have shown excellent performance in oxidation ageing tests. As an illustration how lifetime depends on temperature, Fig. 8 shows the lifetime predictions calculated with $E_{A}=65 \mathrm{~kJ} / \mathrm{mol}$ for field temperatures of $20^{\circ} \mathrm{C}, 30^{\circ} \mathrm{C}$ and $40{ }^{\circ} \mathrm{C}$. The longterm "substitute" internal friction angle of the needle

Table 2 Water properties

\begin{tabular}{|c|c|c|c|}
\hline $\begin{array}{l}\mathrm{Ca}^{2+} \\
(\mathrm{mg} / \mathrm{l})\end{array}$ & $\begin{array}{l}\mathrm{Na}^{+} \\
(\mathrm{mg} / \mathrm{l})\end{array}$ & Description & $\begin{array}{l}\text { Remarks } \\
\text { Note: In a previous test tap water was used instead of DI water }\end{array}$ \\
\hline 316.1 & n.d. & Tap water & As delivered stage \\
\hline 145.5 & n.d. & Tap water after $11,300 \mathrm{~h}$ in contact with sodium bentonite & Consumption of $\mathrm{Ca}^{2+}$ due to cation exchange in bentonite \\
\hline n.d. & 3.8 & DI water & As delivered stage \\
\hline n.d. & 247.0 & DI water after $6150 \mathrm{~h}$ in contact with sodium bentonite & $\begin{array}{l}\text { Continuous refilling with fresh DI water due to evaporation loss } \\
\text { of water }\end{array}$ \\
\hline
\end{tabular}

n.d. Not detectable 


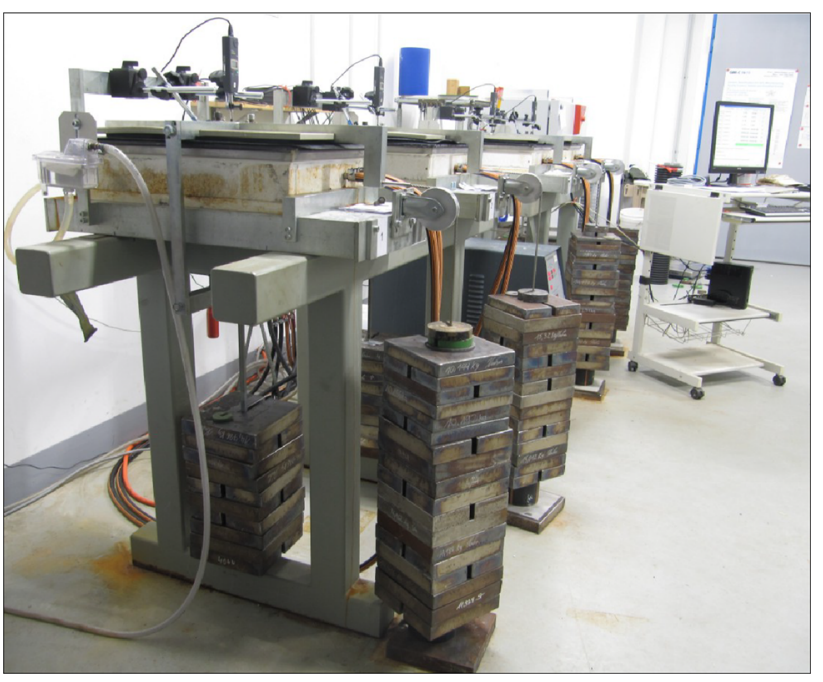

Fig. 3 Shear creep rupture test devices

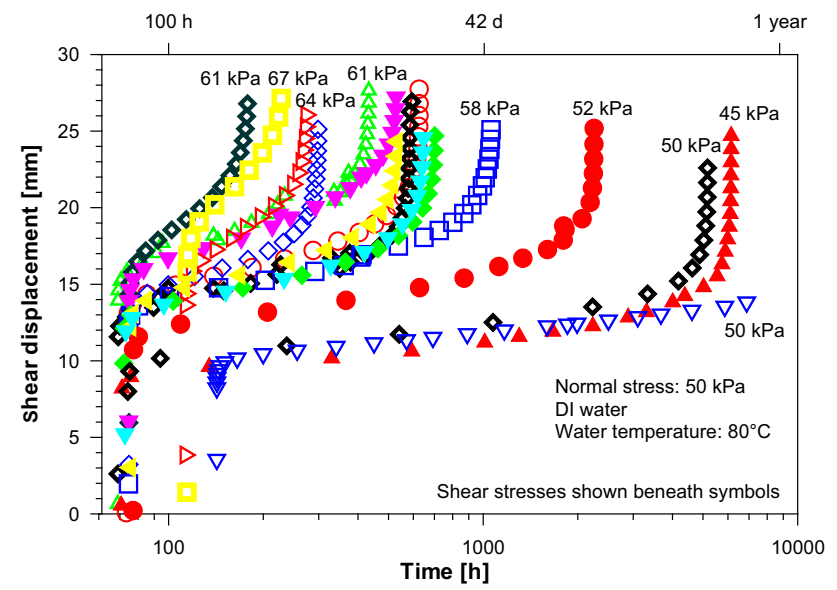

Fig. 4 Shear displacements of a needle punched GCL under different shear stresses

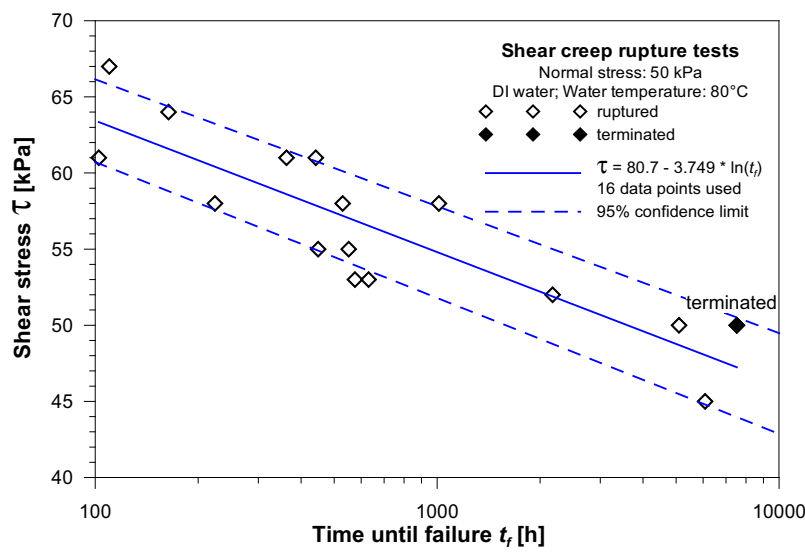

Fig. 5 Shear creep rupture diagram of a needle punched GCL with a $\log$ fit regression line
Table 3 Shear creep rupture test results of a needle punched GCL (normal stress of $50 \mathrm{kPa}$, water temperature of $80^{\circ} \mathrm{C}$, DI water)

\begin{tabular}{llcc}
\hline Test no. & $\begin{array}{l}\text { Shear stress } \\
\tau(\mathrm{kPa})\end{array}$ & $\begin{array}{l}\text { Hydration period } \\
\text { before shear } \\
\text { loading }(\mathrm{h})\end{array}$ & $\begin{array}{l}\text { Time until } \\
\text { failure } \\
t_{f, 80}{ }^{\circ} \mathrm{C}(\mathrm{h})\end{array}$ \\
\hline 1 & 55 & 73.5 & 551.4 \\
2 & 58 & 69.0 & 529.1 \\
3 & 58 & 74.8 & 223.9 \\
4 & 58 & 74.6 & 1011.8 \\
5 & 61 & 69.0 & 362.6 \\
6 & 61 & 74.9 & 102.5 \\
7 & 61 & 74.8 & 441.5 \\
8 & 64 & 115.2 & 163.8 \\
9 & 67 & 114.4 & 109.9 \\
10 & 52 & 77.1 & 2175.4 \\
11 & 53 & 72.0 & 630.6 \\
12 & 45 & 70.7 & 6076.0 \\
13 & 55 & 74.0 & 448.6 \\
14 & 53 & 72.6 & 575.2 \\
15 & 50 & 74.2 & 5098.8 \\
16 & 50 & 142.3 & 7519.2 (terminated) \\
\hline
\end{tabular}

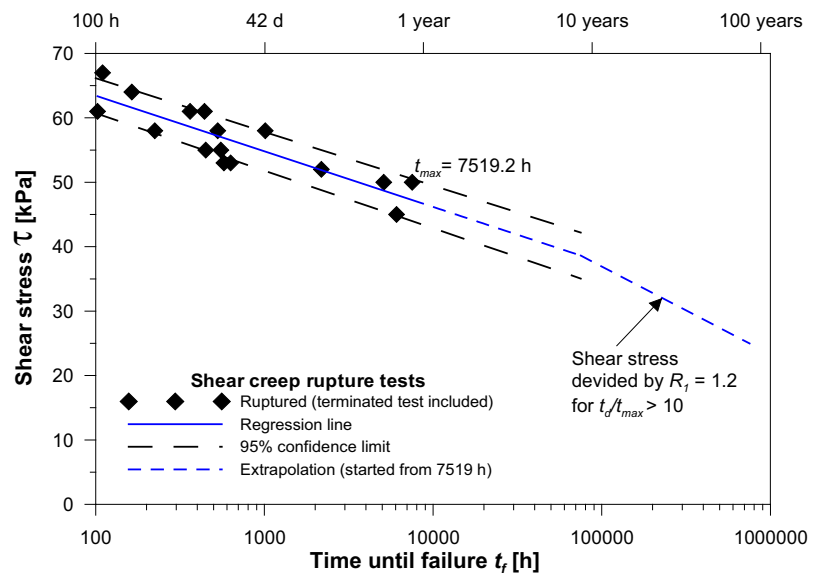

Fig. 6 Prediction of time until failure at $80{ }^{\circ} \mathrm{C}$ due to creep using extrapolation methods

punched GCL is $40.8^{\circ}$ for a service lifetime of 100 years at $30{ }^{\circ} \mathrm{C}$ (Fig. 9). For quality control purposes typically peel tests are performed to control the needling process. Such tests were not part of this study because peeling tests do not represent the real stress situation of a GCL. In an internal shear test, the shear stress and also the normal stress are applied on the entire area of the specimen. Whereas in a peel test, the effect of normal stress is missing and the peel stress is acting more or less on a line perpendicular to the peel force and not on an area. Results from peel tests could - if at all-eventually be used for an evaluation of 


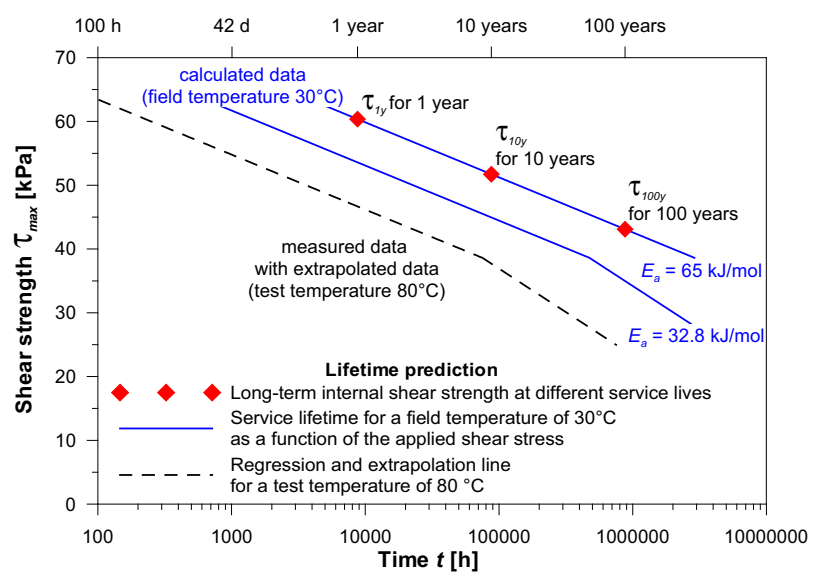

Fig. 7 Estimation of service life of a needle punched GCL using Arrhenius for a functional durability at a long-term field temperature of $30{ }^{\circ} \mathrm{C}$

shear tests at zero normal stress but not as substitution for shear tests.

The short-term internal shear strength of the GCL determined in direct shear tests at a temperature of $30{ }^{\circ} \mathrm{C}$ is $\tau=0.932 \cdot \sigma+64.8$. It can be seen that the determined "short-term" shear stress at $50 \mathrm{kPa}$ normal stress is $111.4 \mathrm{kPa}$ and therefore 2.7 times higher than the predicted "long-term" shear stress calculated for e.g. 100 years (Fig. 9). The short-term secant friction angle at $50 \mathrm{kPa}$ normal stress is $65.8^{\circ}$.

"Short-term" internal shear strength could also be determined on the basis of shear creep rupture tests. Figure 10 shows the "internal shear strength for $1 \mathrm{~min}$ " based on $E_{A}=65 \mathrm{~kJ} / \mathrm{mol}$ and $E_{A}=32.8 \mathrm{~kJ} / \mathrm{mol}$. The internal shear strength for these activation energies are about 110 and $103 \mathrm{kPa}$. Both activation energies show similar internal shear strength in comparison with the result from a direct internal shear test (Fig. 9) at $50 \mathrm{kPa}$ normal stress, which gave shear strength of $111.4 \mathrm{kPa}$.

\section{Ageing of Synthetic Components}

The extrapolation of the shear creep rupture curve and also the extension of the lifetime by using the Arrhenius equation is based on the precondition that the failure modus remains unchanged. This means the failure mode must be a ductile failure for a long time.

Both textile fabrics of the tested GCL have been intensively investigated and selected in very severe accelerated oxidation test conditions with high-pressure autoclave tests (HPAT) acc. to ISO 13438 [8], method C in an aqueous solution of $0.01 \mathrm{M} \mathrm{NaHCO}$ under an oxygen pressure of $5 \mathrm{MPa}$ at an incubation temperature of $80^{\circ} \mathrm{C}$. In comparison to conventional oven ageing tests, the test temperature in HPATs are reduced but the polymers will degrade even faster when they are exposed in HPATs because of the high oxygen pressure applied.

The selected nonwoven GTX (sample no. 10) showed more than $50 \%$ residual tensile strength after exposure for more than 100 days and the selected woven GTX (sample no. 7) demonstrated more than $75 \%$ residual tensile strength after exposure for more than 320 days. Based on this performance and compared with other eight available GTXs used for GCL components shown in Table 4, it can be stated that "excellent" stabilised GTXs are used in the tested needle punched GCL.

From the authors' experience, the oxidation resistance of a "normal stabilised" GTX made of polyolefins in comparison with a GTX made from the same polymer but with a much better stabilisation has a factor of 4-7. This means "excellent stabilised" GTX may have a lifetime prediction of more than 100 years whereas "standard
Table 4 Residual tensile strength of different geotextiles tested at an oxygen pressure of $5 \mathrm{MPa}$ at an incubation temperature of $80^{\circ} \mathrm{C}$ in HPATs acc. to ISO 13438 [28], method $\mathrm{C}$

\begin{tabular}{lclc}
\hline Sample no. & Immersion time $(\mathrm{d})$ & $\begin{array}{l}\text { Residual tensile } \\
\text { strength }\left(\% T_{\max }\right)\end{array}$ & Remarks \\
\hline 1 & 9 & 50 & Woven \\
2 & 27 & 50 & Woven \\
3 & 28 & 54 & Woven \\
4 & 28 & 71 & Woven \\
5 & 16 & 50 & Woven \\
6 & 8 & 50 & Woven \\
7 & 320 & 75 & Woven \\
8 & 34 & 50 & Nonwoven \\
9 & 28 & 76 & Nonwoven \\
10 & 107 & 50 & Nonwoven
\end{tabular}




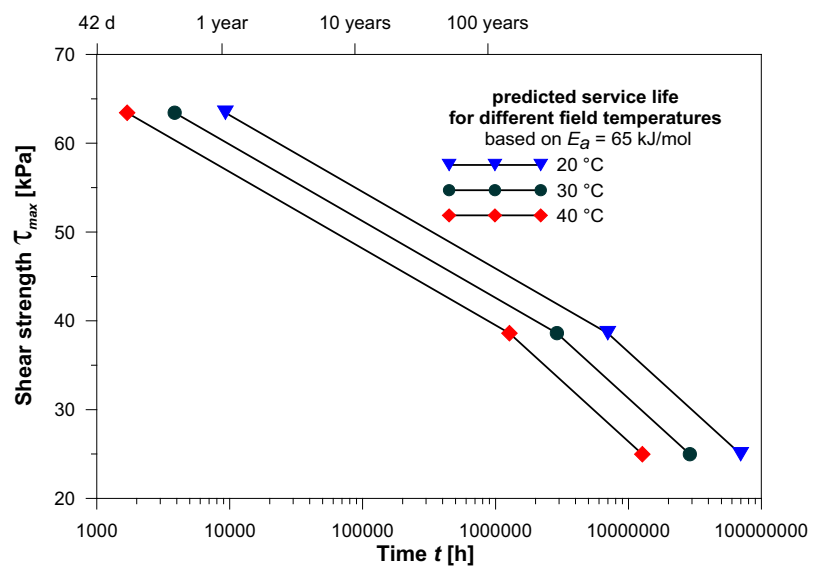

Fig. 8 Predicted service lives for different field temperatures

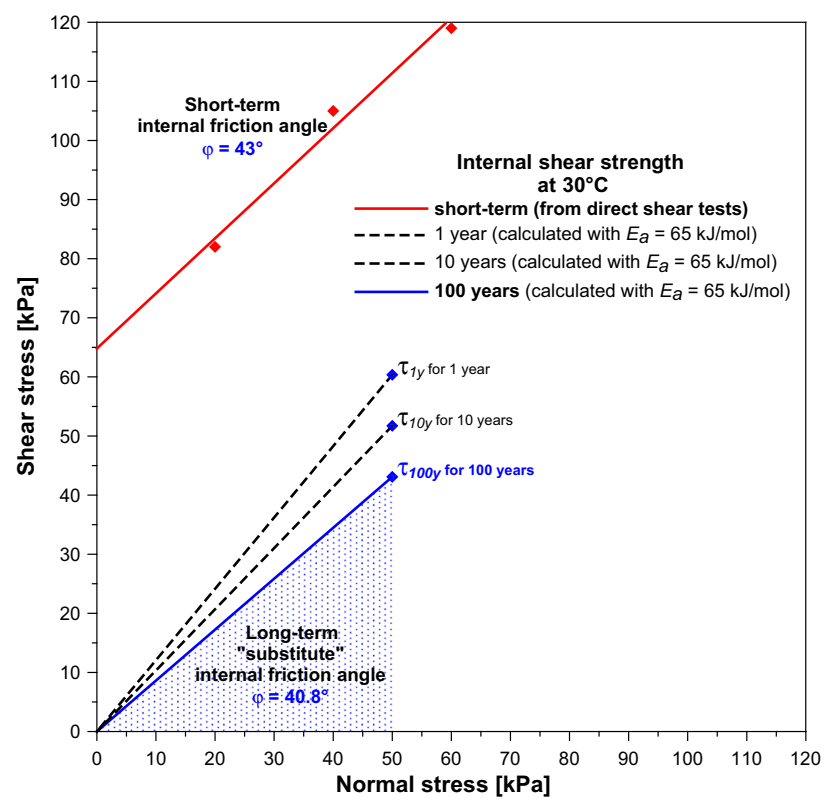

Fig. 9 Internal shear strength of a needle punched GCL at a field temperature of $30{ }^{\circ} \mathrm{C}$

stabilised" geotextiles could last for up to 25 years under temperatures less than $25^{\circ} \mathrm{C}$.

\section{Summary}

In a serious design for a GCL on steep slopes beside the shortterm interface shear strength, the long-term internal shear strength of a GCL has to be known. The interface shear strength is more or less a site specific system test but the internal shear strength is a general material test which is nearly independent from the site conditions. These properties must be available for any GCL which are intended to be used on steep slopes of capping systems in landfills.

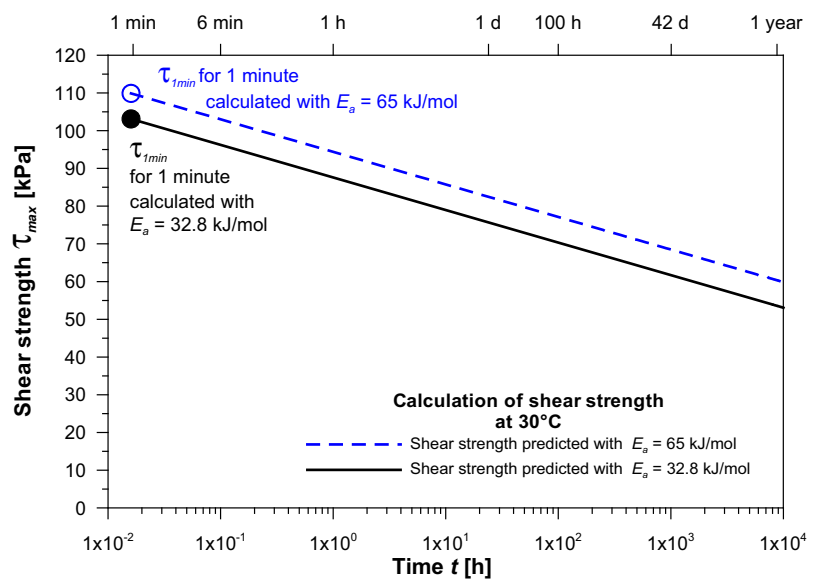

Fig. 10 Determination of "short-term" internal shear strength on the basis of shear creep rupture tests at field temperature of $30{ }^{\circ} \mathrm{C}$ calculated with two different activation energies

The lessons learnt from previous shear creep rupture tests on a stitch bonded GCL are summarized by Zanzinger and Saathoff [2]. They are also relevant in the same way for needle punched GCL. The additional findings for the tested needle punched GCL were:

- The failure mechanism was a combination of pull out of the fibres and a rupture of the fibres.

- The measured data of the shear creep tests resulted in an applicable shear stress of $25 \mathrm{kPa}$ under a normal stress of $50 \mathrm{kPa}$ at a temperature of $80{ }^{\circ} \mathrm{C}$ for 85 years of loading.

- For a field temperature of $30{ }^{\circ} \mathrm{C}$, the applicable shear stress under a normal stress of $50 \mathrm{kPa}$ of the tested GCL was $43 \mathrm{kPa}$ for minimum of 100 years.

- The GCL has proven that it will last for 100 years with the use of "excellent stabilised" synthetic components.

Acknowledgments This work was part of a LAGA project performed by SKZ-German Plastics Center, with the support of CETCO EUROPE Ltd. The mineralogical properties on water samples were determined by Dr. Nathalie Touze-Foltz, Irstea.

\section{References}

1. Madsen F, Nüesch R (1995) Characteristics and sealing effects of bentonite. Geosynthetic clay liners. In: Koerner RM, Gartung E, Zanzinger H (eds) Balkema, Rotterdam, pp 31-49

2. Zanzinger H, Saathoff F (2012) Long-term internal shear strength of a reinforced GCL based on shear creep rupture tests. Geotext Geomembr (Special Issue on Geosynthetic Clay Liners) 33:43-50

3. Müller WW, Jakob I, Seeger S, Tatzky-Gerth R (2008) Long-term shear strength of geosynthetic clay liners. Geotext Geomembr 26(2):130-144

4. Müller W, Büttgenbach B, Jakob I, Mann H (2003) Comparison of the oxidative resistance of various polyolefin geotextiles. Geotext Geomembr 21:289-315 
5. LAGA Ad hoc-AG (Länderarbeitsgemeinschaft Abfall) (2009) Grundsätze für die Eignungsbeurteilung von geosynthetischen Tondichtungsbahnen als mineralische Dichtung in Oberflächenabdichtungssystemen von Deponien (Bentonitmattengrundsätze) from 19 Jan 2009. www.gewerbeaufsicht.niedersachsen.de. (in German)

6. LAGA Ad hoc-AG (Länderarbeitsgemeinschaft Abfall) (2005) Allgemeine Grundsätze für die Eignungsbeurteilung von Abdichtungskomponenten der Deponieoberflächenabdichtungssysteme
(Allgemeine Grundsätze) from 19.04.2005. AbfallwirtschaftsFakten, 11, April 2005 or www.gewerbeaufsicht.niedersachsen.de. (in German)

7. Li M, Hsuan YG (2004) Temperature and pressure effects on the degradation of polypropylene tape yarns: depletion of antioxidants. Geotext Geomembr 22(6):511-530

8. ISO 13438:2004 Geotextiles and geotextile-related productsscreening test method for determining the resistance to oxidation. ISO International Organization for Standardization, Geneva 